\title{
Molecular Advances on Phytases in Barley and Wheat
}

\author{
Claus Krogh Madsen and Henrik Brinch-Pedersen * \\ Department of Molecular Biology and Genetics, Research Center Flakkebjerg, Aarhus University, 4200-Slagelse, \\ Denmark; ClausKrogh.Madsen@mbg.au.dk \\ * Correspondence: hbp@mbg.au.dk
}

Received: 20 March 2019; Accepted: 15 May 2019; Published: 18 May 2019

\begin{abstract}
Phytases are pro-nutritional enzymes that hydrolyze phytate and make associated nutrients, such as phosphorous, iron, and zinc, bioavailable. Single-stomached animals and humans depend on phytase supplied through the diet or the action of phytase on the food before ingestion. As a result, phytases - or lack thereof-have a profound impact on agricultural ecosystems, resource management, animal health, and public health. Wheat, barley and their Triticeae relatives make exceptionally good natural sources of phytase. This review highlights advances in the understanding of the molecular basis of the phytase activity in wheat and barley, which has taken place over the past decade. It is shown how the phytase activity in the mature grains of wheat and barley can be ascribed to the PAPhy_a gene, which exists as a single gene in barley and in two or three homeologous copies in tetra- and hexaploid wheat, respectively. It is discussed how understanding the function and regulation of PAPhy_a may support the development of improved wheat and barley with even higher phytase activity.
\end{abstract}

Keywords: phytase; wheat; barley; purple acid phosphatase phytase; PAPhy; mature grain phytase activity (MGPA)

\section{Introduction}

Phytases (myo-inositol hexakisphosphate 3-,6- and 5-phosphohydrolase, EC 3.1.3.8, EC 3.1.3.26 and EC 3.1.3.72) are phosphatases that can initiate the stepwise hydrolysis of phytate (IP6, myoinositol-(1,2,3,4,5,6)-hexakisphosphate) and thereby provide phosphate $(\mathrm{P})$, inositol phosphates, and inositol for a range of cellular activities [1]. In addition to purely scientific inquiries, phytase research has for many years been driven by the urgent need for improving utilization of phytate-phosphorus in diets for single-stomached animals, such as pigs and poultry, and to reduce the anti-nutritional effect of non-digested IP6 chelating micronutrients in the digestive tracts of humans and animals. As such, phytases can be regarded as tools for managing global phosphate resources and for alleviating human micro-nutrient deficiencies mainly in the developing world.

IP6 is the main storage form of phosphate in plants, typically amounting $2 / 3$ of the total P content in the seed (Table 1). IP6 is a strong chelator and exists in the plant seeds as an insoluble mixed salt with cations called phytin. In cereals and many other plant seeds, phytin forms spherical crystalloid inclusions called globoids inside protein storage vacuoles. The globoids are the principal site of phosphorous $(\mathrm{P})$, potassium $(\mathrm{K})$ and magnesium $(\mathrm{Mg})$ in the mature cereal grain but they also contain calcium $(\mathrm{Ca})$, iron $(\mathrm{Fe})$, zinc $(\mathrm{Zn})$, copper $(\mathrm{Cu})$, manganese $(\mathrm{Mn})$, sodium $(\mathrm{Na})$, sulfur $(\mathrm{S})$, and protein $[2,3]$. 
Table 1. Total P, IP6 bound P, proportion of IP6 bound P, and phytase activity in wheat, barley and other cereals seeds. The number of samples is $\mathrm{n}$ and \pm denotes the standard deviation. The range is given if $n \geq 2$. Data from [4] ${ }^{1},[5]^{2},[6]^{3}$.

\begin{tabular}{|c|c|c|c|c|c|}
\hline Cereal & $n$ & $\begin{array}{c}\text { Total P } \\
\text { (\% of Dry Matter) }\end{array}$ & $\begin{array}{c}\text { Total IP6 P } \\
\text { (\% of Dry Matter) }\end{array}$ & $\begin{array}{l}\text { Percent IP6 out } \\
\text { of Total P }\end{array}$ & $\begin{array}{l}\text { Phytase Activity } \\
\text { (FTU/kg)* }\end{array}$ \\
\hline Wheat $^{1}$ & 13 & $0.33 \pm 0.02$ & $0.22 \pm 0.02$ & $67 \pm 4.8$ & $1193 \pm 223$ \\
\hline Wheat $^{2}$ & 18 & $0.40 \pm 0.04$ & $0.29 \pm 0.04$ & $73 \pm 8.1$ & $2886 \pm 645$ \\
\hline Wheat ${ }^{3}$ & 30 & $0.29 \pm 0.03$ & $0.23 \pm 0.03$ & $79 \pm 0.07$ & $1637 \pm 275$ \\
\hline Barley $^{1}$ & 9 & $0.37 \pm 0.02$ & $0.22 \pm 0.01$ & $60 \pm 2.4$ & $582 \pm 178$ \\
\hline Barley $^{2}$ & 15 & $0.42 \pm 0.4$ & $0.26 \pm 0.03$ & $63 \pm 3.5$ & $2323 \pm 648$ \\
\hline Barley $^{3}$ & 21 & $0.31 \pm 0.03$ & $0.19 \pm 0.02$ & $61 \pm 0.04$ & $1016 \pm 330$ \\
\hline Rye $^{1}$ & 2 & $0.36(0.35-0.36)$ & $0.22(0.20-0.23)$ & $61 \pm(56-66)$ & $5130(4132-6127)$ \\
\hline Rye $^{2}$ & 13 & $0.36 \pm 0.02$ & $0.24 \pm 0.2$ & $67 \pm 5.0$ & $6016 \pm 1578$ \\
\hline Rye $^{3}$ & 6 & $0.34 \pm 0.03$ & $0.20 \pm 0.01$ & $59 \pm 0.02$ & $5147 \pm 649$ \\
\hline Triticale $^{1}$ & 6 & $0.37 \pm 0.02$ & $0.25 \pm 0.02$ & $67 \pm 3.7$ & $1688 \pm 227$ \\
\hline Triticale $^{2}$ & 12 & $0.40 \pm 0.03$ & $0.28 \pm 0.03$ & $70 \pm 5.4$ & $2799 \pm 501$ \\
\hline Oats ${ }^{1}$ & 6 & $0.36 \pm 0.03$ & $0.21 \pm 0.04$ & $59 \pm 11$ & $42 \pm 50$ \\
\hline Oats $^{2}$ & 6 & $0.37 \pm 0.01$ & $0.25 \pm 0.02$ & $67 \pm 5.4$ & $496 \pm 35$ \\
\hline Oats $^{3}$ & 9 & $0.29 \pm 0.02$ & $0.17 \pm 0.03$ & $59 \pm 0.07$ & $84 \pm 39$ \\
\hline Maize $^{1}$ & 11 & $0.28 \pm 0.03$ & $0.19 \pm 0.03$ & $68 \pm 5.9$ & $15 \pm 18$ \\
\hline Maize $^{3}$ & 7 & $0.32 \pm 0.01$ & $0.18 \pm 0.01$ & $78 \pm 0.01$ & $70 \pm 7$ \\
\hline Rice $^{4}$ & 1 & & & & 72 \\
\hline
\end{tabular}

Micronutrients are also chelated by phytate in food and feed, and hydrolysis is most wanted for improving micronutrient bioavailability. The anti-nutritional effect of phytate is in particular regarded as critical for Fe and $\mathrm{Zn}$, where phytate is considered the single most important anti-nutritional compound for the bioavailability of these two micronutrients [7]. Iron deficiency is the primary cause of anemia and ranks among the most widespread nutrient deficiencies, estimated to affect 1.6 billion people worldwide [8]. Iron deficiency anemia has been linked to maternal and prenatal mortality, and to impairment of cognitive skills and physical activity [9]. For zinc, around 800,000 child deaths worldwide per year are attributable to Zn deficiency [10] because it significantly increases the risk of diarrhea, pneumonia, and malaria. Moreover, $\mathrm{Zn}$ deficiency has been linked to the morbidity and mortality of children younger than five [11].

Humans and single-stomached animals have insufficient phytase activity in their digestive tract unless it is provided by the diet. Unfortunately, major food and feed components like rice, maize and soybeans contribute with phytate but negligible phytase [4]. Because of the missing phytase activity, the phytate passes largely un-digested through the single-stomached animals' digestive tract and enters the environment when their manure is spread on agricultural fields. Moreover, to ensure that farm animals get the phosphate needed, bio-available mined $\mathrm{P}$ is added to the feed. However, this strategy has become critical in many regions of the world where intense livestock production and spreading of manure with high levels of undigested phytate $\mathrm{P}$ on oversupplied agricultural soil leads to run-off of phosphorus to aquatic ecosystems. The resulting eutrophication is a severe environmental risk [12]. However, also from a resource perspective, inefficient utilization of plant phytate $\mathrm{P}$ is inappropriate. $\mathrm{P}$ is a non-renewable resource, essential for efficient agricultural production, and complete depletion of mined P will have unmanageable consequences for global food production [13]. 


\section{Plant and Microbial Phytases}

IP6 is resistant to most phosphatases whereas the lower inositol phosphates can be degraded by a wider range of phosphatases. Phosphatases that can initiate the dephosphorylation of IP6 are classified as phytases. So far, four classes of phytases have been identified: (1) Histidine acid phosphatase (HAP), (2) purple acid phosphatase (PAP), (3) cysteine phosphatase (CP) and (4) $\beta$-propeller phytase (BPP). Each phytase type has unique structural features due to their distinct catalytic apparatus that allows them to utilize phytate as a substrate in various environments [14].

For decades, applied phytase research was focusing mainly on microbial phytases and to our knowledge, all commercial phytases currently used for feed supplementation are microbial enzymes belonging to the HAP class [14]. Similarly, until recently, microbial HAP phytases were used exclusively for increasing plant seeds phytase activity through transgenesis. However, scientific achievements in recent years have led to a substantially increased knowledge based on the complements of phytases, in particular barley and wheat, and have demonstrated significant potentials of their phytases as highly stable and potent enzymes with potentials both in feed and food (see later).

\section{Mature Grain Phytase Activity}

When hydrated, the mature seed tissues activate a battery of preformed hydrolytic enzymes that degrades the large internal pool of IP6 but also storage compounds like lipids, carbohydrates, and proteins. When ungerminated seeds are used as feedstuffs, this battery of enzymes constitutes all plant-derived hydrolytic activities. We refer to this as the first wave of activity and for phytase, it constitutes what is called the mature grain phytase activity (MGPA). In parallel with imbibition, the embryo synthesizes and secretes the plant hormone gibberellic acid. The aleurone and the scutellum layer of the embryo are thereby turned into secretory tissues where a wide range of hydrolytic enzymes are synthesized and secreted into the endosperm for degradation of cell walls, starch grains and storage proteins-the second wave of hydrolysis [2].

Cereals generally express phytases to assist in their IP6 metabolism but the MGPA varies several orders of magnitude. This is in strong contrast to the modest variation in total and proportional content of seed IP6 (Table1).

\section{Classes of Phytases in Barley and Wheat}

In wheat and barley, two types of phytases have been described, phytases belonging to the HAP class and phytases belonging to the PAP class of phosphatases [1]. The HAP phytases belong to the multiple inositol polyphosphate phosphatase (MINPP) group [15]. MINPP phytases have been reported to be expressed both during grain development, and thereby, potentially contribute to the MGPA, and during germination contributing to the second wave of phytate hydrolysis. The PAP phytases are represented by the TaPAPhy_a/bs from wheat and the HvPAPhy_a/bs from barley, respectively. Expression analysis showed that $P A P h y \_a$ genes are preferentially expressed during grain filling whereas the PAPhy_b genes are preferentially expressed during germination [16]. The Km value with phytate as a substrate for recombinant wheat MINPP rTaPhyIIa2 phytase and barley rHvPhyIlb phytase is around ten-fold higher than for the rTaPAPhy_a/b and rHvPAPhy_a/b PAP phytases, indicating PAPhys to be more potent phytases than the HAPhys (Table 2). 
Table 2. Kinetic parameters from HAP and PAPhy phytases from wheat, barley, and Aspergillus ficuum. Data from ${ }^{1}[15],{ }^{2}[16],{ }^{3}[17]$.

\begin{tabular}{|c|c|c|c|c|c|c|}
\hline Class & Enzyme & $\begin{array}{l}K \mathrm{~m} \\
(\mu \mathrm{M})\end{array}$ & $\begin{array}{c}V \max \\
(\mu \mathrm{mol} /(\min \times \mathrm{mg}))\end{array}$ & $\begin{array}{l}\text { Kcat } \\
\left(\mathrm{s}^{-1}\right)\end{array}$ & $\begin{array}{l}\text { Kcat } / K m \\
\left(s^{-1} M^{-1}\right)\end{array}$ & $\underset{\text { Optimum }}{\mathrm{pH}}$ \\
\hline \multirow{4}{*}{$\begin{array}{c}\text { PAP } \\
\text { Phytases }\end{array}$} & rTaPAPhy_a1 ${ }^{2}$ & 35 & 223 & 279 & $796 \times 10^{4}$ & 5.5 \\
\hline & rTaPAPhy_b1 ${ }^{2}$ & 45 & 216 & 270 & $600 \times 10^{4}$ & 5 \\
\hline & rHvPAPhy_a ${ }^{2}$ & 36 & 208 & 260 & $722 \times 10^{4}$ & \\
\hline & rHvPAPhy_b ${ }^{2}$ & 46 & 202 & 253 & $550 \times 10^{4}$ & \\
\hline \multirow{3}{*}{$\begin{array}{c}\text { HAP } \\
\text { Phytases }\end{array}$} & rTaPhyIIa2 1 & 246 & & & & 4.5 \\
\hline & rHvPhyIlb ${ }^{1}$ & 334 & & & & 4.5 \\
\hline & $\begin{array}{l}\text { A. ficuum } \\
\text { phytase }^{3}\end{array}$ & 27 & - & 348 & $129 \times 10^{5}$ & 5.5 \\
\hline
\end{tabular}

The contribution of HvPAPhy_a and HvPAPhy_b to the total MGPA in barley was recently evaluated using CRISPR/Cas and TALEN [18]. TALEN- and CRISPR/Cas9 were used for introducing targeted mutations in the promoter of the barley phytase gene HvPAPhy_a. Barley lines with substantial deletions in the HvPAPhy_a promoter and 5'CDS retained $<5 \%$ normal MGPA. This confirms that the barley PAPhy_a enzyme is the main contributor to the MGPA and can be regarded as the main target for modulating MGPA.

\section{Biochemical Properties and Storage of the PAPhys}

Wheat and barley mainly store phytate in the protein storage vacuoles (PSVs) of the aleurone layer. PAPhy accumulated during grain filling is localized in the same organelles [16]. This suggests that some mechanism protects the phytate from hydrolysis during grain filling. The PSV's are rapidly acidified in response to gibberellic acid as germination commences. A decrease from $\mathrm{pH} 6.6$ to 5.9 was reported in the PSV's of barley protoplasts incubated with $5 \mu \mathrm{M} \mathrm{GA}_{3}$ and the authors speculated that $\mathrm{pH}$ might play a crucial role in regulating vacuolar hydrolases [19]. Recombinant wheat phytases rTaPAPhy_a1 and rTaPAPhy_b1 showed pH optima of 5.5 and 5, respectively [16]. Optima of pH 5 and 6 were measured for seed purified barley phytases P1 (=HvPAPhy_b) and P2 (=HvPAPhy_a) respectively [20]. This shows that the PAPhy's are most active when the PSV is in the acidified lytic, state and the higher pH optimum of preformed PAPhy_a may even be an adaptation, which enhances activity in the earliest stages of germination. Nevertheless, rTaPAPhy_a retained some activity up to $\mathrm{pH} 7.5$ so $\mathrm{pH}$ regulation of the enzyme alone does not offer a satisfying explanation for the protection of phytate against premature hydrolysis. The second layer of $\mathrm{pH}$-dependent protection is provided by the substrate's organization into globoids, which provides some degree of water exclusion and steric hindrance [3]. A membrane surrounds the globoids and immuno-gold localization suggests that PAPhy is located outside this membrane [16,21]. The membrane, therefore, seems to provide an additional layer of protection, by physical separation. The temperature optimum of the recombinant wheat enzymes was 50 and $55{ }^{\circ} \mathrm{C}$, respectively. The temperature curves showed a broad peak with $50 \%$ activity already at $30-35^{\circ} \mathrm{C}$ but decreasing sharply around $60^{\circ} \mathrm{C}$. Optima of 55 and $45^{\circ} \mathrm{C}$ were reported for the seed purified HvPAPhy_a and HvPAPhy_b respectively [20]. The kinetic parameters of recombinant wheat and barley phytases at $36^{\circ} \mathrm{C}$ and $\mathrm{pH} 5$ are summarized in Table 2 . The corresponding values for Aspergillus ficuum phytase are given for comparison [17]. The values for the PAPhys are very similar.

\section{PAPhy Genetics}

The PAPhy_a and PAPhy_b genes are paralogs, which originate from gene duplication in a common ancestor of wheat, barley, and rye (i.e., the Triticeae tribe) [22]. Rice, maize, and sorghum diverged from the Triticeae earlier and carry only one PAPhy gene whereas Brachypodum distachyon has the duplication but lack the conserved PAPhy_a promoter of the Triticeae (Figure 1) [22]. Allopolyploidzation has united the $\mathrm{A}$ and $\mathrm{B}$ genomes to form tetraploid wheat (e.g., durum wheat). Triticum urartu and 
Aegilops speltoides are the closest living relatives of the A and B genomes, respectively. Additional hybridizations have added the Ae. tauschii derived D genome to produce hexaploid wheat (bread wheat, spelt) and the rye derived R genome to produce triticale (Figure 1) [23]. Allopolyploidization results in large-scale gene duplication because most genes in one parent will have a homolog in the other parent species. In allopolyploids, such sets of genes are termed homeologs. Some homeologs may be lost or translocated as the polyploid species continues to evolve but the Triticeae PAPhy gene copy number and chromosomal localization are highly conserved. A single locus of PAPhy_a and PAPhy_ $b$ resides on chromosome 5 and 3, respectively in barley and on the homologous chromosomes on the three subgenomes of wheat [22]. The sequenced diploid members of the Triticum and Aegilops, i.e., Ae. tauschii, Ae. speltoides, Ae. sharonensis, T. Urartu, and T. monococcum also have one PAPhy_a and one PAPhy_b [24]. The chromosomal localization in these relatives has not been determined but it is reasonable to expect a conserved synteny between wheat and its ancestors T. urartu, Ae. Speltoides, and Ae. tauschii. Secale provides an exception since some members of this tribe have two PAPhy_a loci. In the case of domesticated rye, one and two PAPhy_a variants were isolated from the cultivars Imperial and Picasso, respectively [25]. Rye is an outbreeding species, unlike wheat and barley, and tends to have higher allele heterogeneity. Therefore, it cannot be excluded that the two variants from Picasso are alleles of the same gene even though phylogeny suggests that one allele may have been introgressed from S. strictum [25]. Thus, it is not known with certainty if domesticated rye has one or two PAPhy_a loci or whether it is cultivar-dependent.

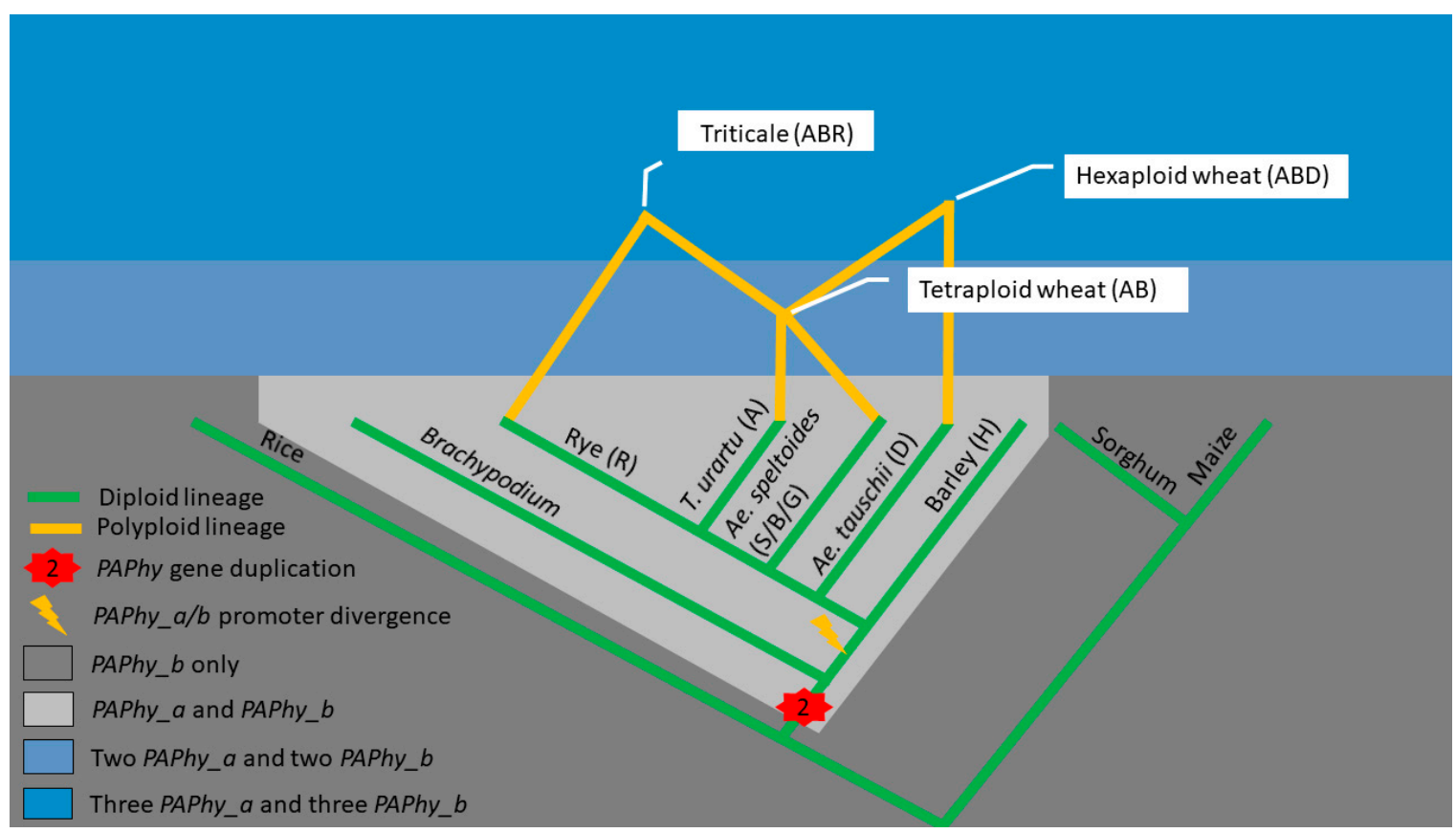

Figure 1. Key events in PAPhy evolution. Gene duplication and divergence of the PAPhy_a/b promoters and further duplications through polyploidization. For simplicity, rye is assumed to have just one PAPhy_a locus, and phylogenetic distance is not drawn to scale.

The intron/exon structure and the respective promoters of PAPhy_ $a$ and PAPhy_b are highly conserved. PAPhy_a has four introns and $P A P h y \_b$ has five. The position and, to a large extent, the size of the introns is conserved between Triticeae species and between the two paralogs [22]. Both genes have a core promoter of $3-400$ base pairs which is conserved in all studied Triticeae. Both promoters have two TATA-boxes and upstream of those reside cis-acting regulatory elements consistent with the differential expression pattern of the two genes (Figure 2). For PAPhy_b, they are ABRE (abscisic-acid-responsive), TGACG (methyl-jasmonate-responsive) and-conserved in all examined PAPhy_b promoters-GARE (gibberellic acid responsive) [22]. The PAPhy_a promoter lacks these hormone responsive elements, 
except TGACG which is found at the very beginning of the conserved sequence. Instead, the most notable feature is a composite element with the consensus 5' GAACATGAGTCATGCATG 3' which is made of the GAMYB binding motif (bold) [26], the odd base palindrome/GCN4 (underlined) $[27,28]$ and the RY element (italic) [29]. These are all elements associated with seed development and storage proteins. Between the composite element and the first TATA box is a G-box motif [22]. Deletion of the odd base palindrome and the RY-element reduce barley MGPA by approximately $40 \%$ whereas deletion of the whole element and an additional 10 base pairs 3 ' reduce MGPA by $75 \%$. Deletions immediately $3^{\prime}$ of the composite element have even more severe effects [14]. It is not clear if this is caused by an unknown cis-acting regulatory element at that position or by the change in distance between the composite element and elements further downstream.

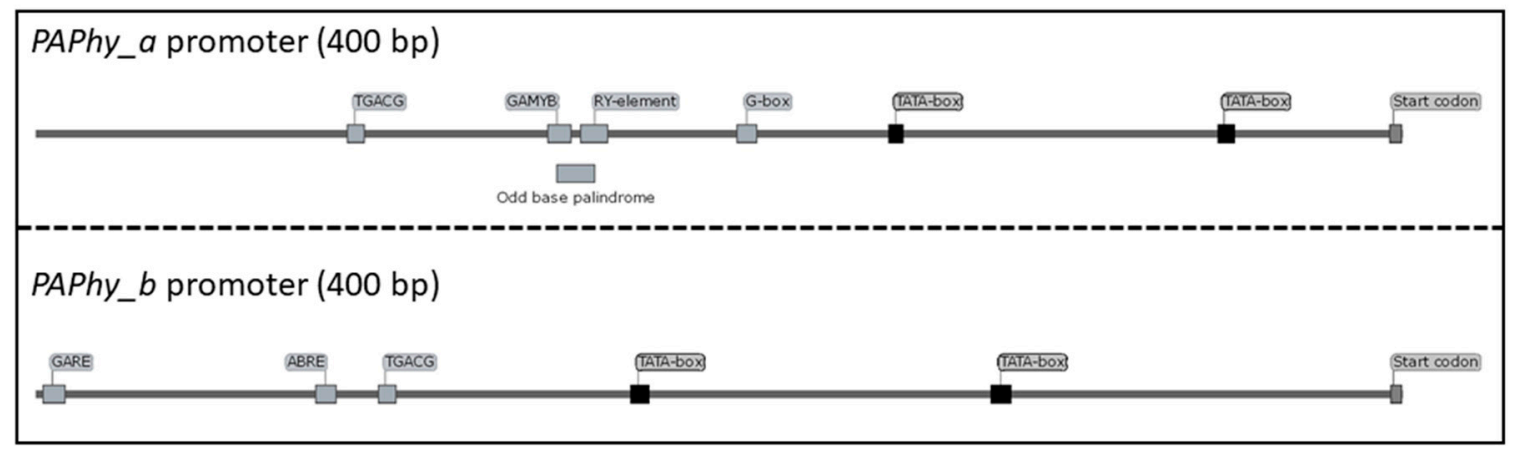

Figure 2. Consensus promoters of PAPhy_ $a$ and $P A P h y \_b$, respectively, showing the most conserved cis-acting regulatory elements.

\section{Applied Potentials of the PAPhys}

Although the PAPhy phytases appear to be somewhat less active than fungal HAP phytases, they certainly have technological potential. Transformation of barley with a genomic clone of HvPAPhy_a, including its native promoter (cisgenesis), more than doubled the MGPA [30]. Moreover, overexpressing HvPAPhy_a using the 35S promoter resulted in a line with impressive $40.000 \mathrm{FTU}$ [31]. This level of MGPA represents more than a 20 fold increase and provides so much activity that $<2 \%$ of the recombinant grains in a feed mixture could theoretically replace conventional phytase supplementation. Moreover, the enzyme activity was highly stable, mature leaves and straw accumulated PAPhy_a and high phytase activity remained after three years of storage. The PAPhy_a was easily extracted in water and could be added to feed or other processes.

The efficacy of a phytase in the digestive tract depends in part on how well intrinsic biochemical parameters, such as $\mathrm{pH}$ optimum, match the environment but also on resistance to proteolysis and inhibition. Feeding experiments are, therefore, necessary to prove efficacy. Early evidence for the efficacy of PAPhy_a was provided by comparing phosphorous and calcium utilization in pigs fed maize and triticale, respectively [32]. In this case, triticale-based feed performed better on both parameters, indicating an effect of the higher MGPA associated with triticale. In humans, an intervention study compared wheat bran with or without phytase (native vs. heat treated) in ileostomy patients. This resulted in recoveries of $40 \%$ vs. $95 \%$ phytate in the ileostomy content [33]. It is also possible to utilize the MGPA to achieve dephytination during food or feed preparation. Up to $96 \%$ of the phytate in whole grain wheat bread could be removed by simply adjusting the $\mathrm{pH}$ during proofing to five [34]. Similarly, fonio (Digitaria exilis) porridge could be dephytinized in one hour at $50{ }^{\circ} \mathrm{C}$ and $\mathrm{pH} 5$ when $25 \%$ of wheat was included. This was demonstrated to significantly increase iron absorption in West African women [35]. Taken together, these studies demonstrate a lot of potential for the utilization of endogenous Triticeae PAPhy_a in food and feed. 


\section{Achieving Higher MGPA with the PAPhys}

Given the high conservation of the PAPhy_a coding sequence and highly similar enzymatic properties of all examined PAPhys, including PAPhy_b as well as rice and maize PAPhy, it seems unlikely that alternative PAPhy_ $a$ alleles, encoding decisively better enzymes, exist. On the other hand, increasing PAPhy_a expression has proven a viable strategy, as discussed. Efforts to increase MGPA by conventional breeding should, therefore, focus on the discovery of more highly expressed PAPhy_a alleles and the elimination of defective alleles.

Polyploids (e.g., wheat) are prone to acquire defective alleles because homeologs on the other subgenomes provide functional redundancy. Nevertheless, defective PAPhy_a alleles may reduce MGPA because the gene copies appear to function in an additive manner as demonstrated by cisgenic gene duplication [30]. Further support for this hypothesis is provided by the discovery of a defective TaPAPhy_a2 gene in the wheat cultivars Skagen and Bob White that correlated with a lower MGPA compared to Chinese Spring, which has three normal loci [22,25]. A similar reduction of phytase activity has been observed in wheat lines with induced deleterious mutations in the PAPhy_a genes (author's unpublished results). It is not known how commonly and how many different defective alleles exist in the elite wheat gene pool. A systematic investigation of this combined with the development of markers for the defective alleles would be helpful in ensuring a minimum MGPA in new cultivars.

More active alleles might be found in crop relatives. Wild emmer (T. dicocoides) can be crossed directly with other tetraploid wheat (e.g., durum wheat) and with hexaploid wheat trough synthetic hexaploids. Alleles from Ae. tauscii can also be introduced by this route or through the "octo-amphiploid bridge" [36]. A higher allele diversity is expected for these species because they have not gone through the bottlenecks of domestication and hexaploidization [37]. A small sampling of wheat and the closest relatives support this assumption [25]. Furthermore, it was found that at least one exotic allele had already been introduced in the elite wheat gene pool in the pursuit of other breeding goals-from $T$. timopheevii. In addition to the abovementioned, einkorn (wild and domesticated), T. urartu, rye, and Ae. speltoides could be used but here the introgression is more complicated.

Another strategy is mutagenesis. A wheat mutant with two to three times increased MGPA has been patented by the authors and co-workers [38]. This "HighPhy" wheat has an SNP in the composite element discussed above. Incremental replacement (1/3, 2/3, and 3/3) of conventional wheat with HighPhy all improved calcium and phosphorous digestibility compared to the control diet in a comprehensive feeding experiment with broiler chicken. Complete replacement with HighPhy wheat even significantly outperformed a control to which the standard dose of microbial phytase was added [39].

With the exception of the Triticeae cereals, none of the major food and feed grains accumulate nutritionally sufficient amounts of phytase during grain development $[4,5]$. Rather, phytase is synthesized de novo during germination in response to gibberellic acid. Introducing a transgene driven by a seed development specific promoter has, therefore, been considered the only realistic approach to introduce preformed phytase in major grains, such as maize, rice, and soybean. However, the recent advances in genome editing may change this because they enable targeted modification of endogenous genes [40]. In theory, this can introduce preformed phytase activity in one of two ways (a) by modifying the promoter of endogenous phytase genes to become active during grain development or $(b)$ by modifying the active site of phosphatases already expressed during grain development so they become phytases. It seems possible to pursue option "a" by combining the lessons of the natural evolution of the PAPhy_a promoter from the PAPhy_b counterpart with target species-specific information on cis-acting regulatory elements involved in seed development-specific expression. The pursuit of option " $\mathrm{b}$ " would have to be guided by structural biology but has the advantage that mutations could be tested in a heterologous system before the more laborious plant gene editing. It is also likely that this approach would require smaller changes to the target gene sequence because a single base mutation is enough to change one critical amino acid. 
Proteinaceous inhibitors are known for many hydrolases including amylases, proteases, and xylanases. To our knowledge, such an inhibitor has never been reported for a phytase of microbial or plant origin. However, it was recently discovered that barley grain extracts do inhibit Aspergillus phytase. The inhibition could be reduced by the addition of pepstatin A. This suggests that the apparent inhibition is caused by an aspartic acid proteolytic activity [41]. It would represent a new and important variable, if plants use specialized proteases rather than conventional inhibitors to counteract phytases, e.g., from pathogens.

In conclusion, preformed wheat and barley phytase has the potential to counter the negative effects of phytate in the nutrition of single-stomached farm animals and humans alike. Realizing this potential depends on awareness because minor adjustments to processing may be needed. Generally, these adjustments should ensure that the phytase is not inactivated before ingestion or, alternatively, that the phytase has optimal conditions to perform the dephytination before inactivation. The higher the MGPA, the better the chances of a successful dephytination. Characterization of the PAPhy_a gene over the past decade should be most helpful for plant breeders who make MGPA a priority.

Funding: This research received no external funding.

Conflicts of Interest: The authors are co-inventors of patent WO 2012/146597Al.

\section{References}

1. Brinch-Pedersen, H.; Madsen, C.K.; Holme, I.B.; Dionisio, G. Increased understanding of the cereal phytase complement for better mineral bio-availability and resource management. J. Cereal Sci. 2014, 59, 373-381. [CrossRef]

2. Bethke, P. From Storage Compartment to Lytic Organelle: The Metamorphosis of the Aleurone Protein Storage Vacuole. Ann. Bot. 1998, 82, 399-412. [CrossRef]

3. Bohn, L.; Josefsen, L.; Meyer, A.S.; Rasmussen, S.K. Quantitative Analysis of Phytate Globoids Isolated from Wheat Bran and Characterization of Their Sequential Dephosphorylation by Wheat Phytase. J. Agric. Food Chem. 2007, 55, 7547-7552. [CrossRef] [PubMed]

4. Eeckhout, W.; De Paepe, M. Total phosphorus, phytate-phosphorus and phytase activity in plant feedstuffs. Anim. Feed Sci. Technol. 1994, 47, 19-29. [CrossRef]

5. Steiner, T.; Mosenthin, R.; Zimmermann, B.; Greiner, R.; Roth, S. Distribution of phytase activity, total phosphorus and phytate phosphorus in legume seeds, cereals and cereal by-products as influenced by harvest year and cultivar. Anim. Feed Sci. Technol. 2007, 133, 320-334. [CrossRef]

6. Viveros, A.; Centeno, C.; Brenes, A.; Canales, R.; Lozano, A. Phytase and Acid Phosphatase Activities in Plant Feedstuffs. J. Agric. Food Chem. 2000, 48, 4009-4013. [CrossRef]

7. Bouis, H.E. Special Issue on Improving Human Nutrition Through Agriculture. Food Nutr. Bull. 2000, 21, 351-578.

8. De Benoist, B.; Cogswell, M.; Egli, I.; McLean, E. Worldwide prevalence of anaemia 1993-2005. In WHO Global Database of Anaemia; WHO: Geneva, Switzerland, 2008.

9. Stoltzfus, R.J.; Mullany, L.; Black, R.E. Iron deficiency anemia. In Comparative Quantification of Health Risks: Global and Regional Burden of Disease Attribution to Selected Major Risk Factors; Ezzati, M., Lopez, A.D., Rodgers, A., Murray, C.J., Eds.; World Health Organization: Geneva, Switzerland, 2004; ISBN 9241580313.

10. Brown, K.H.; Rivera, J.A.; Bhutta, Z.A.; Gibson, R.S.; King, J.C.; Lonnerdal, B. Chapter 2: Assessment of the Risk of Zinc Deficiency in Populations. Food Nutr. Bull. 2004, 25, S130.

11. Yakoob, M.Y.; Theodoratou, E.; Jabeen, A.; Imdad, A.; Eisele, T.P.; Ferguson, J.; Jhass, A.; Rudan, I.; Campbell, H.; Black, R.E.; et al. Preventive zinc supplementation in developing countries: impact on mortality and morbidity due to diarrhea, pneumonia and malaria. BMC Public Health 2011, 11, S23. [CrossRef] [PubMed]

12. Schindler, D.W.; Carpenter, S.R.; Chapra, S.C.; Hecky, R.E.; Orihel, D.M. Reducing Phosphorus to Curb Lake Eutrophication is a Success. Environ. Sci. Technol. 2016, 50, 8923-8929. [CrossRef] [PubMed]

13. Cordell, D.; Drangert, J.-O.; White, S. The story of phosphorus: Global food security and food for thought. Glob. Environ. Chang. 2009, 19, 292-305. [CrossRef] 
14. Lei, X.G.; Porres, J.M.; Mullaney, E.J.; Brinch-Pedersen, H. Phytase: Source, Structure and Application. In Industrial Enzymes: Structure, Function and Applications; Polaina, J., MacCabe, A., Eds.; Springer: Dordrecht, The Netherlands, 2007; pp. 505-530. ISBN 978-1-4020-5376-4.

15. Dionisio, G.; Holm, P.B.; Brinch-Pedersen, H. Wheat (Triticum aestivum L.) and barley (Hordeum vulgare L.) multiple inositol polyphosphate phosphatases (MINPPs) are phytases expressed during grain filling and germination. Plant Biotechnol. J. 2007, 5, 325-338. [CrossRef]

16. Dionisio, G.; Madsen, C.K.; Holm, P.B.; Welinder, K.G.; Jørgensen, M.; Stoger, E.; Arcalis, E.; Brinch-Pedersen, H. Cloning and characterization of purple acid phosphatase phytases from wheat, barley, maize, and rice. Plant Physiol. 2011, 156. [CrossRef] [PubMed]

17. Ullah, A.H.J.; Phillippy, B.Q. Substrate selectivity in Aspergillus ficuum phytase and acid phosphatases using myo-inositol phosphates. J. Agric. Food Chem. 1994, 42, 423-425. [CrossRef]

18. Holme, I.B.; Wendt, T.; Gil-Humanes, J.; Deleuran, L.C.; Starker, C.G.; Voytas, D.F.; Brinch-Pedersen, H. Evaluation of the mature grain phytase candidate HvPAPhy_a gene in barley (Hordeum vulgare L.) using CRISPR/Cas9 and TALENs. Plant Mol. Biol. 2017, 95, 111-121. [CrossRef]

19. Swanson, S.J.; Jones, R.L. Gibberellic Acid Induces Vacuolar Acidification in Barley Aleurone. Plant Cell 1996, 8, 2211, LP-2221. [CrossRef] [PubMed]

20. Greiner, R.; Jany, K.-D.; Larsson Alminger, M. Identification and Properties of myo-Inositol Hexakisphosphate Phosphohydrolases (Phytases) from Barley (Hordeum vulgare). J. Cereal Sci. 2000, 31, 127-139. [CrossRef]

21. Jiang, L.; Phillips, T.E.; Hamm, C.A.; Drozdowicz, Y.M.; Rea, P.A.; Maeshima, M.; Rogers, S.W.; Rogers, J.C. The protein storage vacuole. J. Cell Biol. 2001, 155, 991, LP-1002. [CrossRef]

22. Madsen, C.K.; Dionisio, G.; Holme, I.B.; Holm, P.B.; Brinch-Pedersen, H. High mature grain phytase activity in the Triticeae has evolved by duplication followed by neofunctionalization of the purple acid phosphatase phytase (PAPhy) gene. J. Exp. Bot. 2013, 64. [CrossRef]

23. IWGSC A chromosome-based draft sequence of the hexaploid bread wheat (Triticum aestivum) genome. Science 2014, 345, 1251788. [CrossRef]

24. IWGSC IWGSC-Blast. Available online: https://urgi.versailles.inra.fr/blast_iwgsc/blast.php (accessed on 17 May 2019).

25. Madsen, C.K.; Petersen, G.; Seberg, O.; Brinch-Pedersen, H. Evolution and diversity of PAPhy_a phytase in the genepool of wheat (Triticum aestivum L., Poaceae). Genet. Resour. Crop Evol. 2017, 64. [CrossRef]

26. Guo, W.; Yang, H.; Liu, Y.; Gao, Y.; Ni, Z.; Peng, H.; Xin, M.; Hu, Z.; Sun, Q.; Yao, Y. The wheat transcription factor TaGAMyb recruits histone acetyltransferase and activates the expression of a high-molecular-weight glutenin subunit gene. Plant J. 2015, 84, 347-359. [CrossRef]

27. De Pater, S.; Katagiri, F.; Kijne, J.; Chua, N.-H. bZIP proteins bind to a palindromic sequence without an ACGT core located in a seed-specific element of the pea lectin promoter. Plant J. 1994, 6, 133-140. [CrossRef] [PubMed]

28. Müller, M.; Knudsen, S. The nitrogen response of a barley C-hordein promoter is controlled by positive and negative regulation of the GCN4 and endosperm box. Plant J. 1993, 4, 343-355. [CrossRef]

29. Bäumlein, H.; Nagyt, I.; Villarroel, R.; Inzé, D.; Wobus, U. Cis-analysis of a seed protein gene promoter: the conservative RY repeat CATGCATG within the legumin box is essential for tissue-specific expression of a legumin gene. Plant J. 1992, 2, 233-239.

30. Holme, I.B.; Dionisio, G.; Brinch-Pedersen, H.; Wendt, T.; Madsen, C.K.; Vincze, E.; Holm, P.B. Cisgenic barley with improved phytase activity. Plant Biotechnol. J. 2012, 10. [CrossRef]

31. Holme, I.B.; Dionisio, G.; Madsen, C.K.; Brinch-Pedersen, H. Barley HvPAPhy_a as transgene provides high and stable phytase activities in mature barley straw and in grains. Plant Biotechnol. J. 2017, 15. [CrossRef]

32. Pointillart, A.; Fourdin, A.; Fontaine, N. Importance of Cereal Phytase Activity for Phytate Phosphorus Utilization by Growing Pigs Fed Diets Containing Triticale or Corn. J. Nutr. 1987, 117, 907-913. [CrossRef]

33. Sandberg, A.-S.; Andersson, H. Effect of Dietary Phytase on the Digestion of Phytate in the Stomach and Small Intestine of Humans. J. Nutr. 1988, 118, 469-473. [CrossRef] [PubMed]

34. Türk, M.; Carlsson, N.-G.; Sandberg, A.-S. Reduction in the Levels of Phytate During Wholemeal Bread Making; Effect of Yeast and Wheat Phytases. J. Cereal Sci. 1996, 23, 257-264. [CrossRef] 
35. Koréissi-Dembélé, Y.; Fanou-Fogny, N.; Moretti, D.; Schuth, S.; Dossa, R.A.M.; Egli, I.; Zimmermann, M.B.; Brouwer, I.D. Dephytinisation with intrinsic wheat phytase and iron fortification significantly increase iron absorption from fonio (Digitaria exilis) meals in West African women. PLoS ONE 2013, 8, e70613. [CrossRef] [PubMed]

36. Singh, N.; Wu, S.; Tiwari, V.; Sehgal, S.; Raupp, J.; Wilson, D.; Abbasov, M.; Gill, B.; Poland, J. Genomic Analysis Confirms Population Structure and Identifies Inter-Lineage Hybrids in Aegilops tauschii. Front. Plant Sci. 2019, 10, 9. [CrossRef]

37. Feuillet, C.; Langridge, P.; Waugh, R. Cereal breeding takes a walk on the wild side. Trends Genet. 2008, 24, 24-32. [CrossRef] [PubMed]

38. Brinch-Pedersen, H.; Madsen, C.K.; Dionisio, G.; Holm, P.B. High expression cereal phytase gene. WO 2012/146597 Al. 2012. Available online: https://patents.google.com/patent/WO2012146597A1/en (accessed on 17 May 2019).

39. Scholey, D.; Burton, E.; Morgan, N.; Sanni, C.; Madsen, C.K.; Dionisio, G.; Brinch-Pedersen, H. P and Ca digestibility is increased in broiler diets supplemented with the high-phytase HIGHPHY wheat. Animal 2017, 11. [CrossRef]

40. Yin, K.; Gao, C.; Qiu, J.-L. Progress and prospects in plant genome editing. Nat. Plants 2017, 3, 17107. [CrossRef] [PubMed]

41. Bekalu, Z.E.; Madsen, C.K.; Dionisio, G.; Brinch-Pedersen, H. Aspergillus ficuum phytase activity is inhibited by cereal grain components. PLoS ONE 2017, 12. [CrossRef]

(C) 2019 by the authors. Licensee MDPI, Basel, Switzerland. This article is an open access article distributed under the terms and conditions of the Creative Commons Attribution (CC BY) license (http://creativecommons.org/licenses/by/4.0/). 